\title{
Impact of shorter MDR tuberculosis regimen drugs on heart rate variability in MDR tuberculosis patients at tertiary care hospital
}

\author{
Disha S. Patel*, Chetankumar R. Acharya
}

Department of Pharmacology, Government Medical College, Surat, Gujarat, India

Received: 14 May 2021

Accepted: 04 June 2021

*Correspondence:

Dr. Disha S. Patel,

Email: doc.disha94@gmail.com

Copyright: (C) the author(s), publisher and licensee Medip Academy. This is an open-access article distributed under the terms of the Creative Commons Attribution Non-Commercial License, which permits unrestricted non-commercial use, distribution, and reproduction in any medium, provided the original work is properly cited.

\begin{abstract}
Background: Tuberculosis is major cause of death in India. Analysis of heart rate variability is one of the most popular methods of autonomic nervous system evaluation. Shorter MDR-TB regimen drugs affect both central nervous system as well as peripheral nervous system. Existing research suggests that active pulmonary tuberculosis causes ANS dysfunction. So, by HRV measurement impact of shorter MDR-TB regimen drugs on autonomic dysfunction can be correlated. Aim of the current investigation was to evaluate effect of shorter MDR-TB regimen drugs on cardiac autonomic regulation in MDR-TB patients with respect to heart rate variability as a parameter.

Methods: Fifty newly diagnosed MDR-TB patients of either gender on shorter MDR- TB regimen were enrolled in this study after taking consent. After 20 minutes rest, ECG was taken by "physiopac digital polygraph" software for 5 minutes. Two follow-up HRV assessments were done on $2^{\text {nd }}$ month and $4^{\text {th }}$ or $6^{\text {th }}$ month of treatment. HRV was calculated by root mean square deviation of successive differences between adjacent RR intervals (RMSSD) and low frequency and high frequency ratio.

Results: Repeated measures ANOVA showed no statistically significant difference in HRV parameters between baseline, 2 months and 6 months groups. So, sympathetic and parasympathetic modulation in terms of HRV remains unchanged during treatment of MDR-TB with shorter MDR-TB regimen drugs.

Conclusions: Shorter MDR-TB regimen drugs don't have any significant impact on HRV in MDR- TB patients, No correlation was observed between HRV and heart rate in MDR-TB patients.
\end{abstract}

Keywords: Shorter MDR-TB regimen, Autonomic dysfunction, Heart rate variability, Digital polygraph

\section{INTRODUCTION}

Heart rate variability (HRV) is a physiological phenomenon of variation in the time interval between heartbeats. It is measured by variation in "R-R interval" of each heartbeat. Variation in the time interval of each heartbeat is a physiological phenomenon. Heart acts not only as a pump but also as a global coordinator in synchronization with other body functions. Because of influence of many factors, heart does not maintain the exact same rhythm from one beat to the next. It reacts to any stimulus by increasing or decreasing its rhythm so that body can adapt to any change and this adaptation is called HRV. ${ }^{1}$ Cardiovascular system is controlled and influenced by its unique intrinsic nervous system and autonomic nervous system. Analysis of HRV is one of the most popular methods of Autonomic Nervous System (ANS) evaluation. HRV mainly depends on interaction of sympathetic and parasympathetic nervous system. HRV indices are not direct indices of tonic activity of sympathetic and parasympathetic nervous system, but they are resultant of their influence on effectors, which are receptor on sinus node cell of heart. ${ }^{2}$

Existing research work suggest that during course of active pulmonary tuberculosis there is dysfunction of $\mathrm{ANS},{ }^{3}$ Which may have long term implication on its functionality. 
Tuberculosis (TB) is ninth leading cause of death worldwide but third in India, ranking above HIV/AIDS. ${ }^{4}$ In India tuberculosis is major health burden. Mortality is high among MDR-TB patients. ${ }^{5}$ WHO updated its treatment guidelines for drug-resistant TB in May 2016 and included a recommendation on the use of the shorter MDR-TB regimen for MDR-TB or rifampicin resistantTB, regardless of patient age or HIV status. ${ }^{6}$ Standardized shorter MDR-TB regimen contains seven drugs and treatment duration of 9-12 months. These drugs individually cause many adverse drug reactions like, increase in heart rate, postural hypotension, peripheral neuropathy, QT prolongation, optic neuropathy, hearing loss, seizures and headache. ${ }^{7-11}$ So, these drugs affects both central nervous system (CNS) as well as peripheral nervous system (PNS). ${ }^{7}$ So, by HRV measurement it can be correlated that whether these adverse drug reactions are due to ANS dysfunction or not. Patients with abnormal HRV have higher rate of morbidity and mortality. ${ }^{12}$ An understanding of HRV and anti-tubercular drugs if clear then it may enlighten the path towards modification of existing therapeutic strategies. Ultimately it will be helpful in decreasing morbidity and mortality in tuberculosis patients.

\section{Aim and objectives}

Aim of current study was to evaluate effect of shorter MDR-TB regimen drugs namely moxifloxacin, kanamycin/amikacin, ethionamide, clofazimine, pyrazinamide, isoniazid, and ethambutol on cardiac autonomic regulation in MDR-TB patients with respect to heart rate variability as a parameter. To achieve this aim primary objective was to measure HRV in MDR-TB patients before starting of treatment, after completion of 2 months treatment and after completion of 6 months treatment with shorter MDR-TB regimen drugs and the secondary objective was to find the value of correlation between HRV and heart rate in MDR-TB patients.

\section{METHODS}

\section{Study design and population}

It was a prospective open label, observational study of total 50 newly diagnosed MDR-TB patients of either gender. All patients of shorter MDR- TB regimen were explained about study and those who were willing to give consent were enrolled in the study. Medicines were given by chest physician according to RNTCP 2019 guidelines. After taking brief history, general examination was done for all patients. Patient selection was also depended on inclusion and exclusion criteria.

\section{Inclusion criteria}

Inclusion criteria for current study were; newly diagnosed MDR-TB patients, age 18-65 years of either gender, not taking any other medications for tuberculosis outside new civil hospital.

\section{Exclusion criteria}

Exclusion criteria for current study were; patients with other co-morbid conditions like HIV, any cardiovascular disease, renal failure, any psychiatric disorder, diabetes and any medication for this disease, pregnant and lactating women and history of smoking or any other addiction.

\section{Procedure}

Pre-treatment or baseline HRV assessment was done before starting of anti-tubercular medications. After 20 minutes rest, ECG was taken by "physiopac digital polygraph" software (Figure 1) for a fixed duration of 5 minutes. Two follow-up HRV assessments were done on $2^{\text {nd }}$ month and $4^{\text {th }}$ or $6^{\text {th }}$ month (after completion of intensive phase) of treatment. Follow-up ECG recordings were also taken by same method and duration. HRV was calculated by root mean square deviation of successive differences between adjacent RR intervals (RMSSD) and low frequency and high frequency ratio (LF/HF ratio). Follow-up values were compared with pre-treatment values of same patient, so here Pre treatment value of RMSSD and LF/HF are considered as baseline.

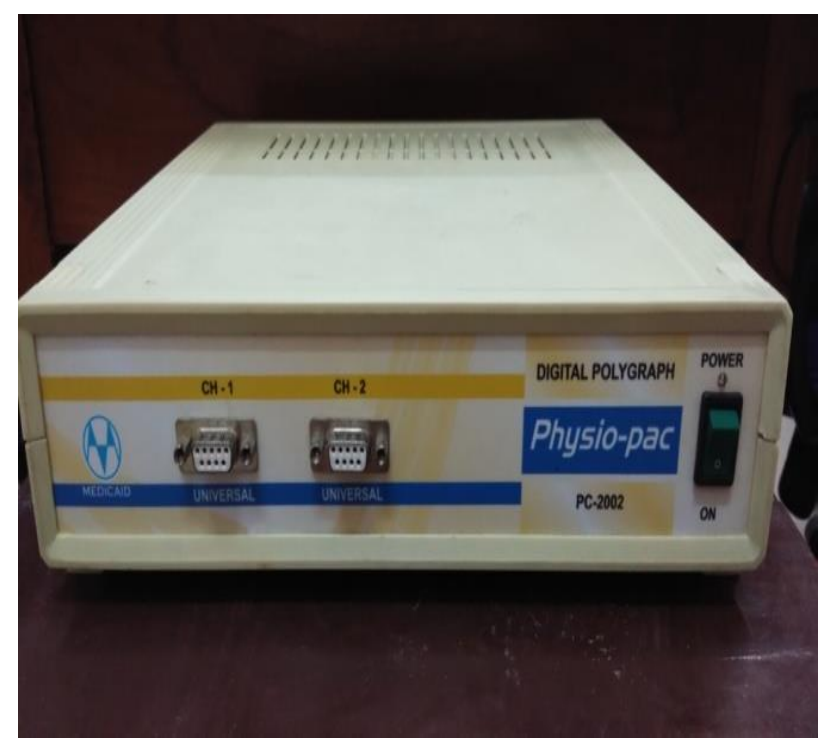

Figure 1: Physiopac digital polygraph.

\section{Estimation of $\mathrm{HRV}$}

All participants were given 20 minutes of rest before recording of $\mathrm{HRV}$, then electrodes were placed on all four limbs and one on chest, HRV was measured for 5 minutes using "physiopac digital polygraph". There are two methods of HRV estimation. ${ }^{13}$

Time domain analysis: The time domain HRV variables were determined by statistical (parametric) analysis using time domain measures, from the N-N interval data, following measures were derived: SDNN (standard deviation of N-N intervals), RMSSD (square root of mean square of successive R-R interval difference), NN50 
(number of interval differences of successive R-R intervals greater than $50 \mathrm{~ms}$ ) and pNN50 (the proportion derived by dividing NN50 by total number of R-R intervals). Out of all these parameters RMSSD is most appropriate for this study, so from time domain variables, value of RMSSD has been taken in consideration for HRV analysis in this study.

Frequency domain analysis: ECG was taken at frequency of $256 \mathrm{~Hz}$. In a particular duration of five minutes of the Rwave of QRS complex was detected by using amplitude criteria and R-R intervals were measured. The duration of 5 minutes was chosen since it is more than particular period valid for HRV analysis. ${ }^{14}$ The fast fourier transformation (FFT) of these R-R intervals verses time plot was carried out at $4 \mathrm{~Hz}$ sampling rate. This gives frequency spectrum of the HRV. The frequency range of $\leq 0.04 \mathrm{~Hz}$ is considered as very low frequency (VLF), $0.04-0.15 \mathrm{~Hz}$ as low frequency (LF) and $0.15-0.40 \mathrm{~Hz}$ as high frequency (HF). The data was obtained from the frequency domain analysis in the conducted study was in terms of LF and HF power ( $\mathrm{LF} / \mathrm{HF}$ ratio). The power of $\mathrm{LF}$ is equated with sympathetic and in HF band is with parasympathetic control. The ratio of LF/HF has been taken in consideration for HRV analysis in this study.

\section{Statistical analysis}

All statistical analysis was done using SPSS 23.0 software. All values were expressed as mean \pm SEM. Statistical analysis was done by repeated measures analysis of variance (ANOVA) test with Greenhouse-Geisser correction and post hoc analysis with Bonferroni correction, $\mathrm{p}<0.05$ was taken as statistical significant.

\section{RESULTS}

In this study out of 50 newly diagnosed MDR-TB patients 27 were male and 23 were female. Age distribution of all patients is shown in (Figure 2).

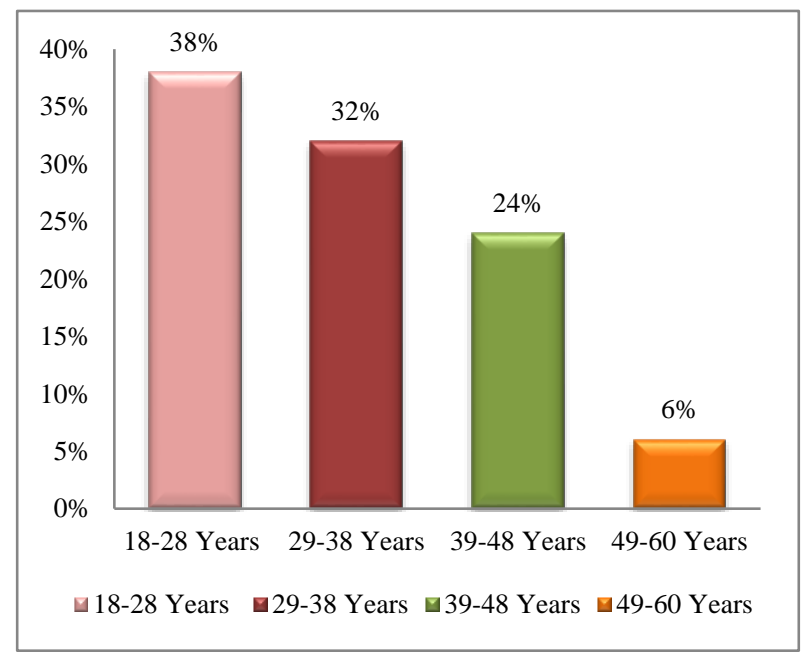

Figure 2: Age distribution of patients receiving shorter MDR- TB regimen drugs. Descriptive statistics of RMSSD.

\section{The root mean square of successive differences between adjacent NN intervals (RMSSD)}

It is an estimate of short-term components of HRV and is essentially the average change in interval between beats. The mean RMSSD values are 44.1, 29.9 ad 45.49 milliseconds for baseline, 2 months and 6 months respectively (Figure 3). A repeated measures ANOVA with a greenhouse-Geisser correction determined that mean RMSSD (HRV) do not differed statistically significant between time points; $F(1.882,92.242)=3.132$, $\mathrm{p}=0.51$. Post hoc analysis with Bonferroni correction revealed that there is no statistically significant difference between mean RMSSD (HRV) of pre-treatment group $(44.11 \pm 7.25)$, after 2 months treatment group (29.90 \pm 3.56$)$ and after 6 months treatment group $(45.49 \pm 8.22)$ of therapy with shorter MDR-TB regimen drugs ( $p>0.05)$.

Pair wise comparison showed that there was no significant difference in RMSSD values between groups, at baseline value to 2 months value and 6 months value $(p>0.05)$ (Table 1). Similarly, there was no significant difference in RMSSD values between groups, at 2 months value to value and 6 months value $(\mathrm{p}>0.05)$.

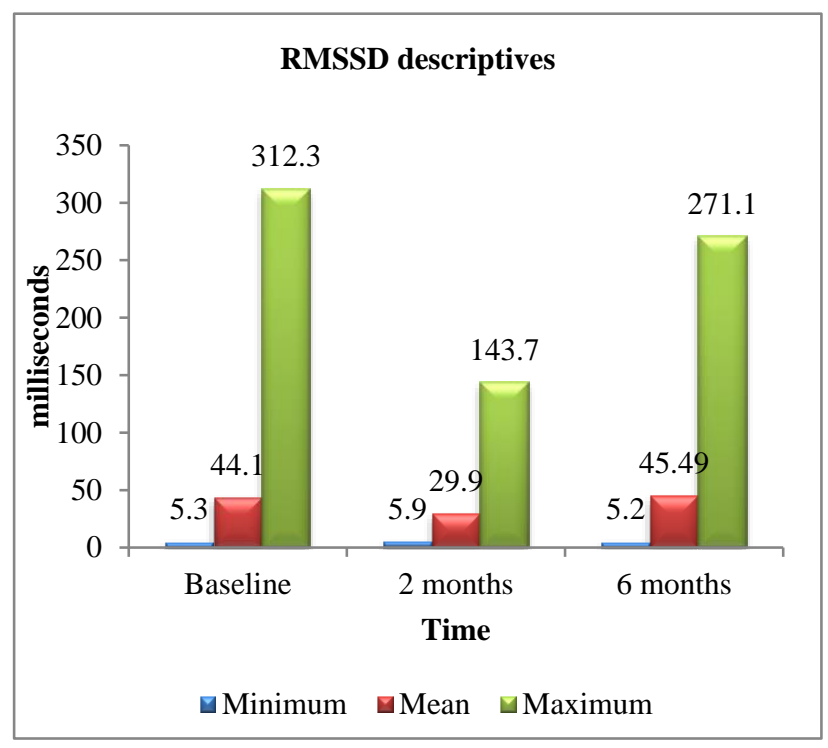

Figure 3: Descriptive statistics of RMSSD.

Table 1: Repeated measures ANOVA pair wise comparison of heart rate variability of RMSSD at different time intervals.

\begin{tabular}{|lllll|}
\begin{tabular}{|l} 
Time Time \\
(I)
\end{tabular} & $\begin{array}{l}\text { Mean } \\
\text { (J) }\end{array}$ & $\begin{array}{l}\text { Stifference } \\
\text { (I-J), (ms) }\end{array}$ & $\begin{array}{l}\text { error } \\
\text { Significance* }\end{array}$ \\
\hline $\mathbf{1}$ & 2 & 14.202 & 6.908 & 0.135 \\
\hline & 3 & -1.386 & 6.095 & 1.000 \\
\hline $\mathbf{2}$ & 3 & -15.588 & 7.597 & 0.137 \\
\hline
\end{tabular}

*Based on estimated marginal means, adjustment for multiple comparisons: Bonferroni, the mean difference is significant at the 0.05 level. Here, 1=RMSSD (HRV) at baseline, 2=RMSSD (HRV) two months and 3=RMSSD (HRV) six months. 


\section{Ratio of low frequency to high frequency $(\mathrm{LF} / \mathrm{HF})$}

LH/HF ratio estimates balance between sympathetic and parasympathetic nervous system. The mean LH/HF ratio was 4.93, 4.74 and 5.07 for baselines, 2 months and 6 months respectively (Figure 4). A repeated measures ANOVA with a greenhouse-Geisser correction determined that mean LH/HF ratio (HRV) do not differed statistically significant between time points; F $(1.938,94.940)=0.472$, $\mathrm{p}=0.619$. Post hoc analysis with Bonferroni correction revealed that there is no statistically significant difference between mean LH/HF ratio (HRV) of pre-treatment group $(4.93 \pm 0.25)$, after 2 months treatment group $(4.74 \pm 0.23)$ and after 6 months treatment group $(5.07 \pm 0.30)$ of therapy with shorter MDR-TB regimen drugs $(p>0.05)$. Pair wise comparison showed that there was no significant difference in $\mathrm{LH} / \mathrm{HF}$ ratio values between groups, at baseline value to 2 months value and 6 months value $(\mathrm{p}>0.05)$ (Table 2$)$. Similarly, there was no significant difference in $\mathrm{LH} / \mathrm{HF}$ ratio values between groups, at 2 months value to 6 months value $(\mathrm{p}>0.05)$

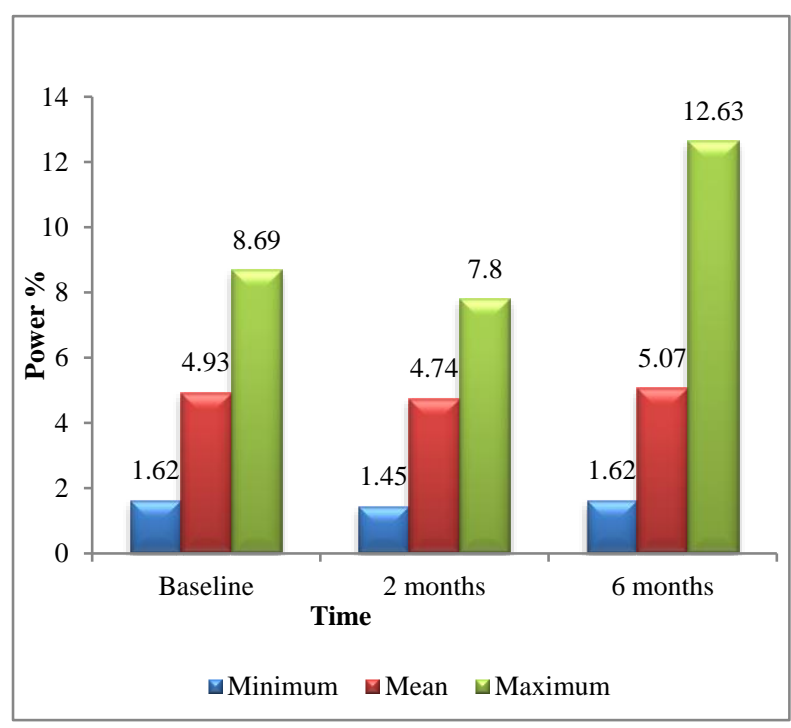

Figure 4: Descriptive statistics of LF/HF ratio.

\section{Heart rate}

Here, heart rate is taken in consideration to find correlation between HRV and heart rate in MDR-TB patients. Mean heart rate is $78.8,81.32$ and 82.2 beats/minute for baseline, 2 months and 6 months respectively (Figure 5). A repeated measures ANOVA with a greenhouse-Geisser correction determined that mean heart rate differed statistically significant between time points $\mathrm{F}(1.993,97.668)=3.715$, $\mathrm{p}=0.028$. Post hoc analysis with Bonferroni correction revealed that there is no statistically significant difference between mean heart rate of pre-treatment group $(78.80 \pm 1.37)$ and after 2 months treatment group (81.32 \pm 1.30$), \mathrm{p}>0.05$. But there is statistically significant difference between mean heart rate of pre-treatment group $(78.80 \pm 1.37)$ and after 6 months treatment group
$(82.20 \pm 1.04)$ of therapy with shorter MDR-TB regimen drugs, $\mathrm{p}<0.05$.

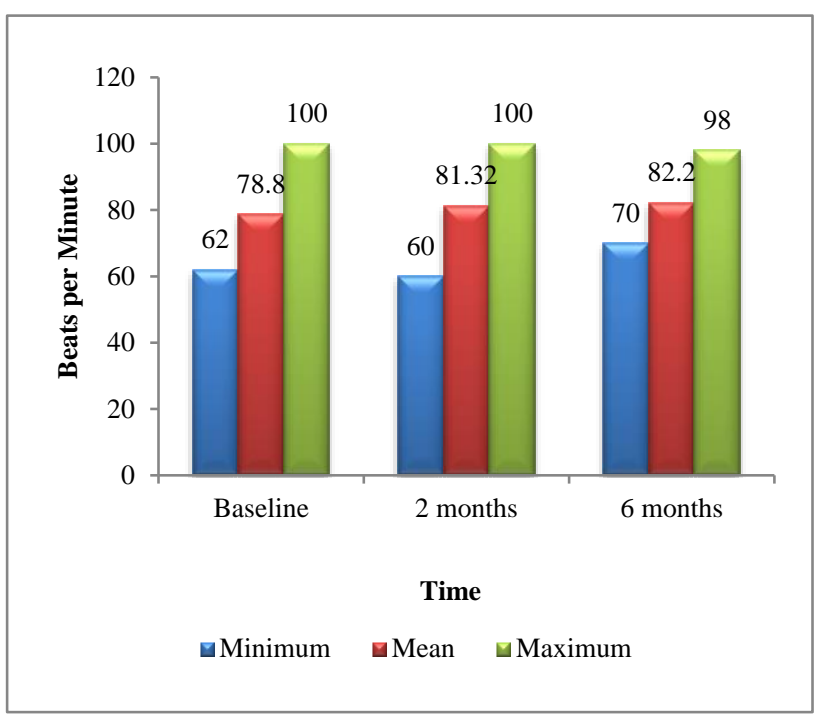

Figure 5: Descriptive statistics of heart rate.

Table 2: Repeated measures ANOVA pair wise comparison of heart rate variability of $\mathrm{LH} / \mathrm{HF}$ ratio at different time intervals.

\begin{tabular}{|lllll|}
\hline $\begin{array}{l}\text { Time } \\
(I)\end{array}$ & $\begin{array}{l}\text { Time } \\
(J)\end{array}$ & $\begin{array}{l}\text { Mean } \\
\text { difference } \\
\text { (I-J), } \\
\text { (Power \%) }\end{array}$ & $\begin{array}{l}\text { Std. } \\
\text { Error }\end{array}$ & Significance* \\
\hline $\mathbf{1}$ & 2 & 0.188 & 0.339 & 1.000 \\
\hline & 3 & -0.142 & 0.314 & 1.000 \\
\hline $\mathbf{2}$ & 3 & -0.330 & 0.366 & 1.000 \\
\hline
\end{tabular}

*Based on estimated marginal means, adjustment for multiple comparisons: Bonferroni, the mean difference is significant at the 0.05 level. Here, $1=\mathrm{LH} / \mathrm{HF}$ ratio (HRV) at baseline, $2=\mathrm{LH} / \mathrm{HF}$ ratio (HRV) two months, $3=\mathrm{LH} / \mathrm{HF}$ ratio (HRV) six months.

Table 3: Repeated measures ANOVA pair wise comparison of heart rate at different time intervals.

\begin{tabular}{|lllll|}
\hline $\begin{array}{l}\text { Time } \\
(\mathrm{I})\end{array}$ & $\begin{array}{l}\text { Time } \\
(\mathrm{J})\end{array}$ & $\begin{array}{l}\text { Mean } \\
\text { difference } \\
(\mathrm{I}-\mathrm{J}),\end{array}$ & $\begin{array}{l}\text { Std. } \\
\text { Error }\end{array}$ & Significance* \\
\hline $\mathbf{1}$ & 2 & -2.520 & 1.259 & 0.153 \\
\hline & 3 & $-3.400^{*}$ & 1.324 & 0.040 \\
\hline $\mathbf{2}$ & 3 & -0.880 & 1.299 & 1.000 \\
\hline
\end{tabular}

*Based on estimated marginal means, adjustment for multiple comparisons: Bonferroni, the mean difference is significant at the 0.05 level. Here, $1=$ heart rate at baseline, $2=$ heart rate at two months, $3=$ heart rate at six months.

Pair wise comparison showed that there was no significant difference in heart rate values between groups, at baseline value to 2 months value (Table 3$),(p>0.05)$. But, there was significant difference in heart rate values between groups, at baseline value to 6 months value $(\mathrm{p}<0.05)$. There was no significant difference in heart rate values between groups, 
at 2 months value to 6 months value $(\mathrm{p}>0.05)$. To know a correlation between HRV and heart rate we have compared RMSSD (time domain measure of HRV) and heart rate at different time points. To find the correlation between HRV and heart rate pearson correlation coefficient was used and from HRV parameters RMSSD was compared with HR at different time intervals. The correlation coefficient (or " $r$ ") is $0.036,0.231$ and 0.048 for pre-treatment, 2 months and 6 months respectively (Table 4). Pearson correlation coefficient test showed that there is no significant correlation between HRV and heart rate at any point of time.

Table 4: Pearson correlation coefficient test showing relationship between RMSSD (HRV) and heart rate $(\mathbf{n}=\mathbf{5 0})$.

\begin{tabular}{|llll|}
\hline Parameters & \multicolumn{1}{|l}{$\begin{array}{l}\text { RMSSD } \\
\text { (ms) }\end{array}$} & $\begin{array}{l}\text { Heart } \\
\text { rate } \\
\text { (bpm) }\end{array}$ \\
\hline $\begin{array}{l}\text { Pre } \\
\text { treatment } \\
\text { RMSSD } \\
\text { (ms) }\end{array}$ & $\begin{array}{l}\text { Pearson } \\
\text { correlation }\end{array}$ & 1 & 0.036 \\
\cline { 2 - 4 } & $\begin{array}{l}\text { Significance } \\
\text { (2-tailed) }\end{array}$ & - & 0.806 \\
\hline $\begin{array}{l}\text { RMSSD } \\
\text { after 2 } \\
\text { months } \\
\text { (ms) }\end{array}$ & $\begin{array}{l}\text { Pearson } \\
\text { correlation }\end{array}$ & 1 & 0.231 \\
\hline $\begin{array}{l}\text { Significance } \\
\text { RMSSD } \\
\text { after 6 } \\
\text { months } \\
\text { (ms) }\end{array}$ & $\begin{array}{l}\text { Pearson } \\
\text { correlation }\end{array}$ & - & 0.107 \\
\hline $\begin{array}{l}\text { Significance } \\
\text { (2-tailed) }\end{array}$ & - & 0.048 \\
\hline
\end{tabular}

*Correlation is considered significant at 0.05 level (2-tailed).

\section{DISCUSSION}

Heart rate variability (HRV) is a physiological phenomenon of variation in the time interval between heartbeats. It is measured by variation in "R-R interval" of each heartbeat. HRV is one of the established parameter to evaluate functional aspect of autonomic nervous system (ANS). It is based on the observation that even at rest the duration of RR intervals is not constant but continually fluctuates. Extremely complex neural mechanisms are responsible for these fluctuations and mainly based on interplay between the sympathetic and parasympathetic nervous system. ${ }^{2}$ Decreased HRV is a strong, independent and consistent risk factor for cardiac mortality. So, HRV can be considered as a cardiovascular predictor of mortality. ${ }^{15}$ Existing research work suggest that regulation of the cardiovascular autonomic nervous system is compromised in case of active pulmonary TB, even in the absence of hypoxemia. ${ }^{3}$ Which may have long term implication on functionality of ANS.

Shorter MDR-TB regimen contains various drugs which can lead to various cardiovascular autonomic adverse drug reactions like, moxifloxacin causes QT prolongation and increased heart rate; kanamycin causes increased heart rate; ethionamide causes postural hypotension; clofazimine causes torsade-de-points; ethambutol causes myocarditis and pericarditis. ${ }^{8,10,16-19}$ These adverse drug reactions can lead to sudden cardiac death. But, there is paucity of data regarding, effect of MDR-TB on ANS and effect of shorter MDR-TB regimen drugs on ANS. So, this study was conducted with the aim to evaluate effect of shorter MDR-TB regimen drugs, on cardiac autonomic regulation in MDR-TB patients with respect to heart rate variability as a parameter. In this study, a computerassisted, 5 minutes measurement of HRV was done to evaluate functional aspects of autonomic nervous system activity during the treatment of MDR-TB with shorter MDR-TB regimen drugs. Total three readings were taken $1^{\text {st }}$ at baseline or pre-treatment reading, which was taken before initiation of shorter MDR-TB regimen drugs, $2^{\text {nd }}$ after 2 months of treatment and $3^{\text {rd }}$ after 6 months of treatment. Follow up readings were compared with baseline reading.

RMSSD is the square root of the mean of the sum of the squares of differences between adjacent NN intervals. Extremely low RMSSD signifies true autonomic dysfunction. Age and sex dependent normal values for HRV parameters have not been established yet. But, Vandenberg et al. showed that values of RMSSDs decreases continuously from birth to old age, for the age group of 20 to 59 years, RMSSD values falls between 24.4 to $48.5 \mathrm{~ms}^{15}$ In this study, it was observed that mean RMSSD value was reduced by an average of $14.202 \mathrm{~ms}$ after 2 months of treatment with shorter MDR-TB regimen drugs than that of pre-treatment mean RMSSD value. But, this reduction in mean RMSSD value was not statistically significant $(\mathrm{p}=0.135)$. Mean RMSSD value was increased by an average of $1.386 \mathrm{~ms}$ after 6 months of treatment with shorter MDR-TB regimen drugs than that of pre-treatment mean RMSSD value. But, this increment in mean RMSSD value was not statistically significant $(\mathrm{p}=1.000)$. Mean RMSSD value was increased by an average of $15.588 \mathrm{~ms}$ after 6 months of treatment with shorter MDR-TB regimen drugs than that of 2 months treatment mean RMSSD value. But, this increment in mean RMSSD value was not statistically significant $(\mathrm{p}=0.137)$. So, no significant difference could be seen in the mean values of RMSSD in between all three groups at any point of time $(p=0.51)$.

Low frequency/high frequency (LF/HF) ratio is an indicator of cardiac autonomic balance. If this ratio is increased, it signifies that there is an imbalance between cardiac autonomic activity. Age and sex dependent normal values for HRV parameters have not been established yet. But, Sammito et al showed that for the age group of 20-60 years, LF/HF ratio values falls between 3.63 to 8.32 power\%. ${ }^{20}$

In this study, it was observed that mean $\mathrm{LF} / \mathrm{HF}$ ratio was reduced by an average of 0.188 power\% after 2 months of treatment with shorter MDR-TB regimen drugs than that of pre-treatment mean $\mathrm{LF} / \mathrm{HF}$ ratio. But, this reduction in mean LF/HF ratio was not statistically significant $(p=1.000)$. Mean $\mathrm{LF} / \mathrm{HF}$ ratio was increased by an average 
of 0.142 power\% after 6 months of treatment with shorter MDR-TB regimen drugs than that of pre-treatment mean $\mathrm{LF} / \mathrm{HF}$ ratio. But, this increment in mean $\mathrm{LF} / \mathrm{HF}$ ratio was not statistically significant $(\mathrm{p}=1.000)$. Mean $\mathrm{LF} / \mathrm{HF}$ ratio was increased by an average of 0.330 power $\%$ after 6 months of treatment with shorter MDR-TB regimen drugs than that of 2 months treatment mean LF/HF ratio. But, this increment in mean $\mathrm{LF} / \mathrm{HF}$ ratio was not statistically significant $(\mathrm{p}=1.000)$. So, no significant difference could be seen in the mean values of LF/HF ratio in between all three groups at any point of time $(p=0.619)$. Since heart rate strongly affects HRV, its effects should be taken into account. ${ }^{15}$ So, the purpose of taking heart rate as a variable was to find correlation between HRV and heart rate and also to check whether the shorter MDR-TB regimen drugs have any effect on heart rate. Normally for a healthy individual heart rate ranges between 60 to $100 \mathrm{bpm} .^{21}$

In current study, it was observed that mean heart rate was increased by an average of $2.520 \mathrm{bpm}$ after 2 months of treatment with shorter MDR-TB regimen drugs than that of pre-treatment mean heart rate. But, this increment in mean heart rate was not statistically significant $(\mathrm{p}=0.153)$. Mean heart rate was increased by an average of $3.400 \mathrm{bpm}$ after 6 months of treatment with shorter MDR-TB regimen drugs than that of pre-treatment mean heart rate. This increment in mean heart rate was statistically significant $(p=0.040)$. Mean heart rate was increased by an average of $0.880 \mathrm{bpm}$ after 6 months of treatment with shorter MDRTB regimen drugs than that of 2 months treatment mean heart rate. But, this increment in mean heart rate was not statistically significant $(\mathrm{p}=1.000)$. So, significant difference could be seen in the mean values of heart rate in between all three groups at any point of time $(\mathrm{p}=0.028)$.

Results of this study did not show statistically significant increment or decrement in HRV after treatment with shorter MDR-TB regimen drugs. Heart rate increased with time and showed statistically significant increment. To find the correlation between HRV and heart rate Pearson correlation coefficient was used and from HRV parameters RMSSD was compared with HR at different time intervals. The correlation coefficient (or " $\mathrm{r}$ ") is $0.036,0.231$ and 0.048 for pre-treatment, 2 months and 6 months respectively, which suggest that there was no correlation between HRV and heart rate at any point of time.

\section{Limitations}

For convenience of patient and availability of limited infrastructure only 5 minutes HRV measurement was done, which was not an ideal recording time for detailed explanation of changes in HRV. However availability of sensitive and accurate software, short term recordings can also give us very reliable and informative changes in the HRV indices. Due to availability of limited time for the study and total duration of treatment of MDR-TB with shorter MDR-TB regimen is of 11 months. So follow up was done for 6 months only. Further study may require for long duration and large sample size.

\section{CONCLUSION}

Based on observations made in present study it can be concluded that shorter MDR-TB regimen drugs do not have any significant impact on HRV in MDR-TB patients, No correlation was observed between HRV and heart rate in MDR-TB patients and there was significant increment in heart rate after 6 months of treatment with shorter MDRTB regimen drug. Further research may be carried out to expand horizon in this lucid area of autonomic dysfunctions related to patients of MDR-TB and antitubercular drugs.

\section{ACKNOWLEDGEMENTS}

Authors would like to thank Dr. N. D. Kantharia (retired professor and head department of pharmacology, GMC, Surat), Dr. Parul Vadgama (associate professor, department of respiratory medicine, GMC, Surat) and her staff members for their support. Authors are also thankful to Dr. Naresh Chauhan, assistant professor, department of community medicine, GMC, Surat for helping in statistical analysis of this study and to all staff members of department of pharmacology, GMC Surat for their constant support, encouragement and invaluable suggestions.

\section{Funding: National Tuberculosis Elimination Program (NTEP) \\ Conflict of interest: None declared \\ Ethical approval: The study was approved by the Institutional Ethics Committee}

\section{REFERENCES}

1. Fatisson J, Oswald V, Lalonde F. Influence diagram of physiological and environmental factors affecting heart rate variability: An extended literature overview. Heart Int. 2016;11(1):e32-40.

2. Zygmunt A, Stanczyk J. Methods of evaluation of autonomic nervous system function. Arch Med Sci. 2010;6(1):11-8.

3. Raimondi G, Contini S, Maria Legramante J, Bocchino M, Sacco S, Pallante M, et al. Autonomic nervous system dysfunction in the course of active pulmonary tuberculosis. Respir Med. 2007;101(8): 1804-8.

4. Global tuberculosis report 2017. Available at: https://www.who.int/tb/publications/global_report/gt br2017_main_text.pdf. Accessed on 20 March 2021.

5. India TB Report 2019. Available at: https://tbcindia. gov.in/WriteReadData/India\%20TB\%20Report\%202 019.pdf. Accessed on 20 March 2021.

6. The shorter mdr-tb regimen background, recommendations on the use of the shorter MDR-TB regimen. Available at: https://www.who.int/tb/ Short_MDR_regimen_factsheet.pdf. Accessed on 20 March 2021. 
7. Kass JS, Shandera WX. Nervous system effects of antituberculosis therapy. CNS drugs. 2010;24(8): 655-67.

8. Mason JW, Moon TE. Moxifloxacin increases heart rate in humans. Antibiotics. 2017;6(1):1-9.

9. Ream CR. Respiratory and cardiac arrest after intravenous administration of kanamycin with reversal of toxic effects by neostigmine. JAMA J Am Med Assoc. 1963;186(2):191.

10. Choudhri SH, Harris L, Butany JW, Keystone JS. Clofazimine induced cardiotoxicity: A case report. Lepr Rev. 1995;66(1):63-8.

11. Koide T, Shiba M, Tanaka K, Muramatsu M, Ishida $\mathrm{S}$, Kondo Y, et al. Severe QT interval prolongation associated with moxifloxacin: a case report. Cases J. 2008;1(1):2-5.

12. Sessa F, Anna V, Messina G, Cibelli G, Monda V, Marsala $G$, et al. Heart rate variability as predictive factor for sudden cardiac death. 2018;10(2):166-77.

13. Kleiger RE, Stein PK, Bigger JT. Heart rate variability: Measurement and clinical utility. Ann Noninvasive Electrocardiol. 2005;10(1):88-101.

14. Andrew TN. Guidelines Heart rate variability. Standards of measurement, physiological interpretation, and clinical use. Eur Soc Cardiol. 1987;59: 256-62.

15. van den Berg ME, Rijnbeek PR, Niemeijer MN, Hofman A, Herpen G van, Bots ML, et al. Normal values of corrected heart-rate variability in 10-second electrocardiograms for all ages. Front Physiol. 2018; 9:1-9.
16. Migliori GB, D'Arcy Richardson M, Sotgiu G, Lange C. Multidrug-resistant and extensively drug-resistant tuberculosis in the West. Europe and United States: epidemiology, surveillance, and control. Clin Chest Med. 2009;30(4):637-65.

17. Marcos Abdo Arbex, Marília de Castro Lima Varella, Hélio Ribeiro de Siqueira FAF de M. Antituberculosis drugs: Drug interactions, adverse effects, and use in special situations. Part 2: Second-line drugs. J Bras Pneumol. 2010;36(5)641-56. 2010; 11(3):641-56.

18. Ethionamide V. Monitoring \& management of common adverse effects of MDR/XDR - TB treatment. 2017;3:6782.

19. Arbex MA, Varella M de CL, Siqueira HR de, Mello FAF de. Antituberculosis drugs: Drug interactions, adverse effects, and use in special situations. Part 1: First-line drugs. J Bras Pneumol. 2010;36(5):641-56.

20. Sammito S, Böckelmann I, Med P. Reference Values of heart rate variability reference values for time- and frequency-domain heart rate variability measures. Hear Rhythm. 2016;13(6):1309-16.

21. Arnold JM, Fitchett DH, Howlett JG, Lonn EM, Tardif JC. Resting heart rate: A modifiable prognostic indicator of cardiovascular risk and outcomes? Can J Cardiol. 2008;24:3-8.

Cite this article as: Patel DS, Acharya CR. Impact of shorter MDR tuberculosis regimen drugs on heart rate variability in MDR tuberculosis patients at tertiary care hospital. Int J Basic Clin Pharmacol 2021;10:813-9. 